Article

\title{
Evaluation of Helicobacter pylori Infection, Neutrophil-Lymphocyte Ratio and Platelet-Lymphocyte Ratio in Dyspeptic Patients
}

\author{
Banu Boyuk ${ }^{1}$, Dogukan Saydan ${ }^{2}$, Osman Mavis ${ }^{2}$ and Hande Erman ${ }^{3, *(D)}$ \\ 1 Department of Internal Medicine, Istanbul Kartal Lutfi Kirdar Education and Research Hospital, \\ Istanbul 34865, Turkey; banuilk@gmail.com \\ 2 Department of Internal Medicine, Istanbul GOP Taksim Education and Research Hospital, \\ Istanbul 34250, Turkey; dogukansaydan@hotmail.com (D.S.); osmanmavis@yahoo.com (O.M.) \\ 3 Department of Internal Medicine, Istanbul Fatih Sultan Mehmet Education and Research Hospital, \\ Istanbul 34752, Turkey \\ * Correspondence: handeerman@yahoo.com; Tel.: +90-536-629-8669
}

Received: 10 August 2020; Accepted: 14 September 2020; Published: 17 September 2020

\begin{abstract}
Recent studies have shown a correlation between Helicobacter pylori (H. Pylori) infection and the neutrophil/lymphocyte ratio (NLR) and platelet/lymphocyte ratio (PLR). The aim of this study was to investigate the relationship between $H$. Pylori infection and hematimetric indices in patients with dyspepsia symptoms. Overall, 448 patients who underwent gastroscopy were analyzed retrospectively. Histopathological evaluation of biopsies according to $H$. pylori presence was classified as $H$. Pylori positive and negative groups, which are analyzed in relation with hematimetric indices. NLR and PLR measurements did not show a statistically significant difference between $H$. pylori negative and positive groups $(p>0.05)$. NLR revealed a negative correlation between hemoglobin (HGB), iron, and ferritin measurements in the correlation analysis of the $H$. Pylori positive group $(\mathrm{r}=-0.133, p=0.031 ; \mathrm{r}=-0.270, p=0.002 ; \mathrm{r}=-0.162, p=0.032)$. Again, with PLR, there was a negative correlation between $\mathrm{HGB}$, mean corpuscular volume (MCV), iron, and ferritin measurements $(\mathrm{r}=-0.310, p=0.001, \mathrm{r}=-0.187, p=0.002, \mathrm{r}=-0.335, p=0.001 ; \mathrm{r}=-0.290 ; p=0.001)$. The results of our study do not reveal an association between $H$. pylori presence and inflammatory response, which is evaluated by NLR and PLR measurements in patients with dyspepsia. However, low serum iron and ferritin values of $H$. pylori-positive patients suggest the effect of $H$. pylori on iron metabolism.
\end{abstract}

Keywords: Helicobacter pylori; dyspepsia; neutrophil; lymphocyte; platelet; iron

\section{Introduction}

Helicobacter pylori (H. pylori) is one of the most common chronic bacterial infections in humans. It affects about $50 \%$ of the world's population. Generally, the infection is seen more frequently and acquired earlier in developing countries when compared to developed countries due to various factors, such as geographical location, ethnic features, sanitation conditions, economical structure of the country [1].

Dyspepsia is a collection of symptoms, which has a differential diagnosis and heterogeneous pathophysiology. It is seen at least in $20 \%$ of the population [2]. While $25 \%$ of patients with dyspepsia symptoms have an underlying organic cause (organic dyspepsia), 75\% of them have no underlying organic cause in diagnostic evaluation (functional dyspepsia) [3,4]. H. pylori gastritis is one of the prominent factors in the pathophysiology of functional dyspepsia (FD). H. pylori infection among dyspeptic patients is estimated to be up to 70\%, although it showed regional differences [5]. 
The number of white blood cells (WBC), neutrophil, lymphocyte, platelet count (PLT) and mean platelet volume (MPV) values and ratios between them are used as an inflammatory indicator. Neutrophil/lymphocyte ratio (NLR) and platelet/lymphocyte ratio (PLR) are the most important of these indicators and they were studied recently to determine the severity of various diseases, gastric cancers, and H. pylori infection [6,7]. Neutrophils are the representative components of the innate immune system and lymphocytes represent the adaptive immune system. Furthermore, most of the studies have demonstrated that increased NLR and PLR are associated with active disease associated with known inflammatory markers [8].

Iron deficiency is associated with increased susceptibility of infections, as well as impaired physical and cognitive functions with or without anemia. Since the first case of $H$. pylori infection with iron deficiency anemia reported in 1991, several explanations for the role of $H$. pylori on iron metabolism have been speculated [9]. Although the relationship is not fully understood, bleeding due to chronic gastritis, absorption defects due to achlorhydria or recently elevated hepcidin levels are blamed [10].

From the point of view that $H$. pylori had been linked to various hematologic manifestations, we aimed to determine the relation between the H. pylori infection and the hematimetric parameters, particularly NLR and PLR values in patients with dyspeptic symptoms.

\section{Materials and Methods}

This study is conducted retrospectively at our Internal Medicine Department among 448 outgoing patients and patients who had gastroscopy. Of these, we tested for H. pylori and simultaneously performed a complete blood count to make our selection according to inclusion and exclusion criteria. The study includes the adult patients between 17 and 83 years old who had a gastroscopy and checked for H. pylori levels in our hospital's pathology and endoscopy records. Endoscopic-pathological diagnosis, H. pylori positive-negative cases, white blood cell count (WBC), neutrophil, lymphocyte, platelet count, iron, vitamin B12, folic acid, total iron binding capacity (TIBC), ferritin, and C-reactive protein (CRP) levels of the patients who are subjects of this study are checked. H. pylori positive and negative cases gathered together in the pathology database according to the population at hand. Patients with (1) gastric cancer, (2) gastric lymphoma, (3) pregnancy, (4) the gastroduodenal surgery, (5) patients who have used antibiotics for up to 4 weeks before the study and (6) who have already undergone $H$. pylori eradication treatment, (7) chronic systemic inflammatory disease were excluded from the study.

Neutrophil/lymphocyte ratio (NLR) and platelets/lymphocyte ratio (PLR) are the leukocyte indexes recommended as inflammatory indicators. In our study, the relation between $H$. pylori infection results and neutrophil/lymphocyte ratio (NLR) and platelet/lymphocyte ratio (PLR) is determined.

\section{Endoscopic and Histopathologic Evaluation}

The study includes the cases where gastroscopy had been performed (OLYMPUS GIF TYPE XP190N). Biopsies were taken from antrum and corpus, which were evaluated in terms of $H$. pylori. Findings of the biopsies for $H$. pylori by gastroscopy are examined and recorded retrospectively. All subjects gave their informed consent for inclusion before they participated in the study. This study was conducted in accordance with the Declaration of Helsinki, and the protocol was approved by the Ethics Committee of University of Health Sciences GOP Taksim Education and Research Hospital on 3 May 2017. (Protocol number: 39).

\section{Statistical Analyses}

Frequency, ratio, mean, minimum, maximum, and standard deviation values were used in the descriptive statistics to determine continuous variables. A Student $t$-test was used for comparison of independent and normally distributed two variables. A Mann-Whitney $U$ test was performed for comparison of independent and non-normally distributed variables. The Pearson chi-square test and Fisher's exact test were performed to determine differences between categorical variables. Multiple 
linear logistic regression analysis was performed to determine the effect levels of the parameters. Spearman's correlation tests were used for the correlation analysis. Statistical significance was assessed at $p<0.05$. Statistical analysis was performed by using Number Cruncher Statistical System (NCSS, Kaysville, UT, USA, 2007).

\section{Results}

Clinical and biochemical characteristics according to the presence of $H$. pylori are summarized in Table 1. A total of $263 \mathrm{H}$. pylori-positive patients with a mean age of $47.87 \pm 13.98$ years, comprising 188 females and 75 males, and a total of $185 \mathrm{H}$. pylori-negative patients with a mean age of $51.30 \pm 14.10$ years, comprising 130 females and 55 males, were enrolled in the study. The mean age of $H$. pylori positive group was significantly lower than the $H$. pylori negative group $(p=0.011, p<0.05)$. There were no differences in hemoglobin (HGB), mean corpuscular volume (MCV), leukocyte, neutrophil, lymphocyte, platelet, NLR, and PLR measurements between $H$. pylori-negative patients and H. Pylori-positive patients $(p>0.05)$. Patients with $H$. pylori had statistically significantly lower iron and ferritin compared to those without $H$. pylori ( $p=0.029 ; p=0.003)$. NLR revealed a statistically significant negative correlation between HGB, iron and, ferritin measurements in the correlation analysis of H. Pylori positive group $(\mathrm{r}=-0.133, p=0.031 ; \mathrm{r}=-0.270, p=0.002 ; \mathrm{r}=-0.162, p=0.032)$. Again, with PLR, there was a statistically negative correlation between HGB, MCV, iron and, ferritin measurements $(\mathrm{r}=-0.310, p=0.001, \mathrm{r}=-0.187, p=0.002, \mathrm{r}=-0.335, p=0.001 ; \mathrm{r}=-0.290 ; p=0.001)$ (Table 2). There was no statistical significance regarding both the PLR and NLR ratio distributions between the two groups (Figure 1).

Table 1. Demographic and biochemical characteristics according to the presence of H. pylori.

\begin{tabular}{|c|c|c|c|c|}
\hline & & \multicolumn{2}{|c|}{ H. pylori } & \multirow{2}{*}{$p$} \\
\hline & & Negative (185) Mean \pm sd, n (\%) & Positive (263) Mean \pm sd, n (\%) & \\
\hline \multicolumn{2}{|c|}{ Age (years) } & $51.30 \pm 14.10$ & $47.87 \pm 13.98$ & a 0.011 * \\
\hline \multirow[t]{2}{*}{ Gender } & Male & $55(29.7)$ & $75(28.5)$ & c 0.781 \\
\hline & Female & $130(70.3)$ & $188(71.5)$ & \\
\hline \multicolumn{2}{|c|}{$\operatorname{HGB}(\mathrm{g} / \mathrm{dL})$} & $12.66 \pm 1.56$ & $12.59 \pm 1.67$ & ${ }^{b} 0.501$ \\
\hline \multicolumn{2}{|c|}{$\mathrm{MCV}(\mathrm{fL})$} & $87.57 \pm 6.85$ & $86.55 \pm 7.57$ & b 0.185 \\
\hline \multicolumn{2}{|c|}{ Leukocyte $(\mu \mathrm{L})$} & $682.70 \pm 1607.57$ & $6944.12 \pm 1973.45$ & b 0.647 \\
\hline \multicolumn{2}{|c|}{ Neutrophil $(\mu \mathrm{L})$} & $3781.03 \pm 1273.28$ & $3995.82 \pm 1555.09$ & b 0.278 \\
\hline \multicolumn{2}{|c|}{ Lymphocyte $(\mu \mathrm{L})$} & $2278.65 \pm 580.43$ & $2300.87 \pm 1013.54$ & b 0.373 \\
\hline \multicolumn{2}{|c|}{$\operatorname{NLR}(\%)$} & $1.74 \pm 0.65$ & $1.92 \pm 1.00$ & b 0.338 \\
\hline \multicolumn{2}{|c|}{ PLR $(\%)$} & $118.91 \pm 38.66$ & $125.59 \pm 47.42$ & $\mathrm{~b} 0.237$ \\
\hline \multicolumn{2}{|c|}{ Platelet $(\mu \mathrm{L})$} & $258,718.92 \pm 66,735.34$ & $264,551.33 \pm 75,162.24$ & b 0.502 \\
\hline \multicolumn{2}{|c|}{ Iron $(\mu \mathrm{g} / \mathrm{dL})$} & $67.28 \pm 39.82$ & $56.45 \pm 33.64$ & b 0.029 * \\
\hline \multicolumn{2}{|c|}{$\operatorname{TIBC}(\mu \mathrm{g} / \mathrm{dL})$} & $356.01 \pm 60.33$ & $363.94 \pm 60.20$ & b 0.268 \\
\hline \multicolumn{2}{|c|}{ Ferritin (ng/mL) } & $36.04 \pm 42.36$ & $30.11 \pm 52.80$ & $\mathrm{~b} 0.003^{* *}$ \\
\hline \multicolumn{2}{|c|}{$\mathrm{B} 12(\mathrm{pg} / \mathrm{mL})$} & $268.77 \pm 158.22$ & $278.53 \pm 186.21$ & $\mathrm{~b} 0.859$ \\
\hline \multicolumn{2}{|c|}{ Folic acid $(\mathrm{ng} / \mathrm{mL})$} & $8.72 \pm 4.15$ & $7.27 \pm 2.77$ & ${ }^{b} 0.081$ \\
\hline \multicolumn{2}{|c|}{$\mathrm{CRP}(\mathrm{mg} / \mathrm{L})$} & $6.04 \pm 6.22$ & $5.28 \pm 4.48$ & ${ }^{\mathrm{b}} 0.530$ \\
\hline \multicolumn{2}{|c|}{ Intestinal metaplasia } & $26(14.1)$ & $48(18.3)$ & ${ }^{c} 0.239$ \\
\hline \multicolumn{2}{|c|}{ Atrophy } & $6(3.2)$ & $18(6.8)$ & ${ }^{c} 0.096$ \\
\hline \multicolumn{2}{|c|}{ Gastritis } & $156(84.3)$ & $219(83.3)$ & c 0.766 \\
\hline \multicolumn{2}{|c|}{ Gastric ulcer } & $31(16.8)$ & 45 (17.1) & c 0.933 \\
\hline \multicolumn{2}{|c|}{ Duodenal ulcer } & $14(7.6)$ & $27(10.3)$ & c 0.329 \\
\hline \multicolumn{2}{|c|}{ Esophagitis } & $49(26.5)$ & $77(29.3)$ & ${ }^{c} 0.518$ \\
\hline
\end{tabular}

Abbreviations: HGB, hemoglobin; MCV, mean corpuscular volume; TIBC, total iron binding capacity; NLR, neutrophil/lymphocyte ratio; PLR, platelet/lymphocyte ratio; CRP, c-reactive protein. ${ }^{a}$ Student $\mathrm{t}$-test, ${ }^{\mathrm{b}}$ MannWhitney U test, ${ }^{\mathrm{c}}$ Pearson's chi-squared test, ${ }^{*} p<0.05,{ }^{* *} p<0.01$. 
Table 2. Comparison of NLR and PLR with other parameters in H. pylori-positive patients.

\begin{tabular}{llllll}
\hline & \multirow{2}{*}{$\mathbf{N}$} & \multicolumn{2}{c}{ NLR } & \multicolumn{2}{c}{ PLR } \\
\cline { 3 - 6 } & & \multicolumn{2}{c}{$\mathbf{R}$} & \multicolumn{1}{c}{$p$} & \multicolumn{1}{c}{$\mathbf{R}$} \\
\hline Age (years) & 263 & 0.020 & 0.743 & 0.054 & 0.386 \\
HGB & 263 & -0.133 & $0.031^{*}$ & -0.310 & $0.001^{* *}$ \\
MCV & 263 & -0.084 & 0.173 & -0.187 & $0.002^{* *}$ \\
Leukocyte $(\mu \mathrm{L})$ & 263 & 0.302 & $0.001^{* *}$ & -0.144 & $0.020^{*}$ \\
Neutrophil $(\mu \mathrm{L})$ & 263 & 0.644 & $0.001^{* *}$ & 0.064 & 0.301 \\
Lymphocyte $(\mu \mathrm{L})$ & 263 & -0.596 & $0.001^{* *}$ & -0.622 & $0.001^{* *}$ \\
Platelet $(\mu \mathrm{L})$ & 263 & 0.032 & 0.606 & 0.502 & $0.001^{* *}$ \\
Iron $(\mu \mathrm{g} / \mathrm{dL})$ & 131 & -0.270 & $0.002^{* *}$ & -0.335 & $0.001^{* *}$ \\
TIBC $(\mu \mathrm{g} / \mathrm{dL})$ & 129 & 0.016 & 0.853 & 0.072 & 0.416 \\
Ferritin $(\mathrm{ng} / \mathrm{mL})$ & 175 & -0.162 & $0.032^{*}$ & -0.290 & $0.001^{* *}$ \\
B12 $(\mathrm{pg} / \mathrm{mL})$ & 177 & -0.035 & 0.644 & -0.013 & 0.861 \\
Folic acid $(\mathrm{ng} / \mathrm{mL})$ & 81 & -0.078 & 0.490 & 0.066 & 0.561 \\
CRP $(\mathrm{mg} / \mathrm{L})$ & 52 & 0.006 & 0.967 & -0.085 & 0.548 \\
\hline
\end{tabular}

Abbreviations: HGB, hemoglobin; MCV, mean corpuscular volume; TIBC, total iron binding capacity; NLR, neutrophil/lymphocyte ratio; PLR, platelet/lymphocyte ratio; CRP, c-reactive protein. r: Spearman's correlation coefficient, ${ }^{*} p<0.05,{ }^{* *} p<0.01$.
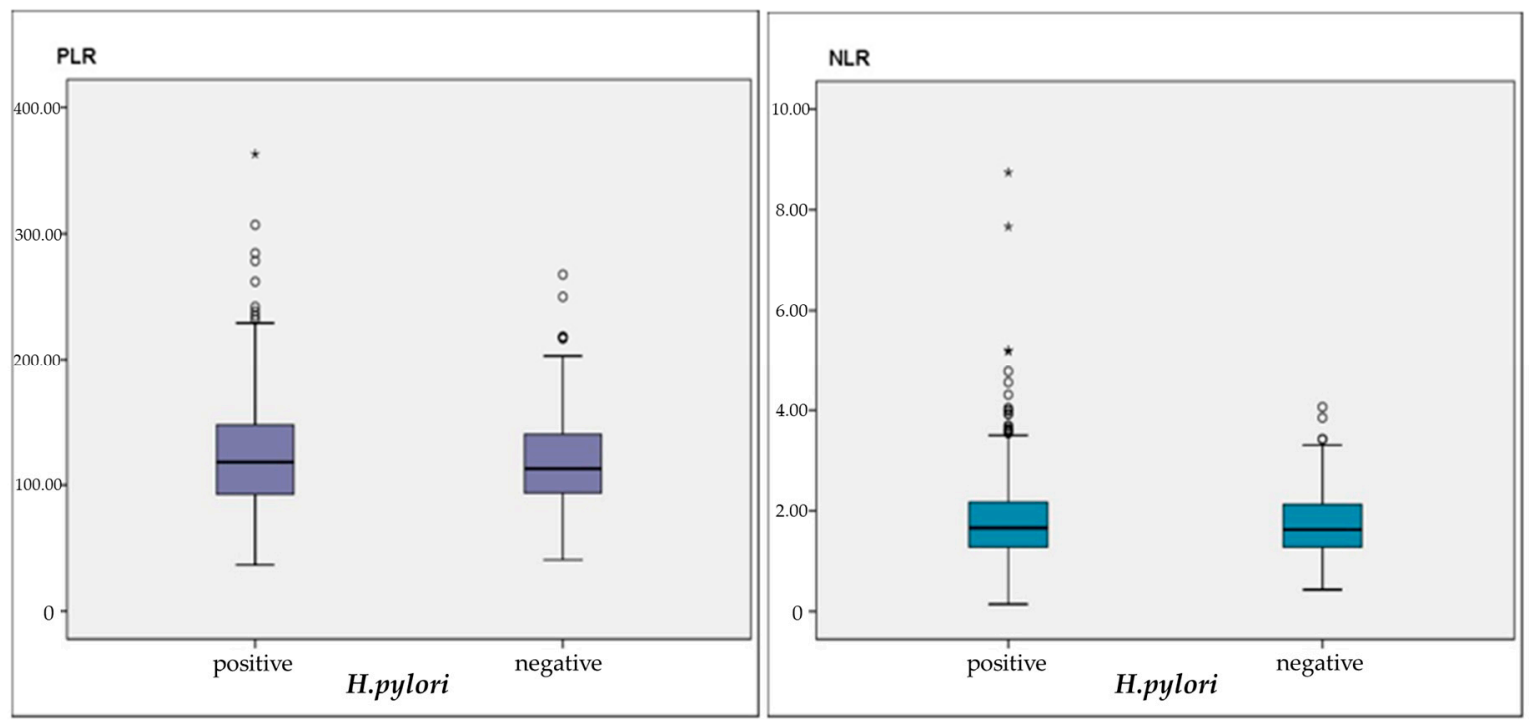

Figure 1. PRL and NLR distribution according to H. pylori presence.

\section{Discussions}

Today, more than $50 \%$ of the world's population is thought to be infected with H. pylori. While prevalence is $40-50 \%$ in developed countries, it is $70-90 \%$ in underdeveloped or developing countries and even for some age groups, it reaches $100 \%$ [11]. One of the attention-grabbing findings of our study is the fact that $H$. pylori-positive patients are younger when compared to $H$. pylori-negative patients. This shows that $H$. pylori infection is acquired in early ages. In a similar manner, study from Eastern Europe revealed $72.1 \%$ positivity for $H$. pylori among 459 adults who were tested by urea breathe test [12]. Another study from Norway with 1624 participants from all ages demonstrated that the prevalence increases gradually with age, except for in the age group above 70 years. They hypothesized that age-related positivity might be the result of lifestyle factors and social activity which broadens common use areas [13].

It is shown that $H$. pylori has a large spectrum of both metabolic and non-metabolic extra-gastric manifestations. A striking study by Isave et al. demonstrated the colonization of H. pylori in the hepatobiliary system of cirrhosis patients with a frequency of 50\% [14]. Their findings support the 
studies that were pointed out toward the H. pylori infection and hepatocellular carcinoma [15]. On the other hand, the relationship between $H$. pylori infection and cardiovascular diseases, chronic metabolic diseases, such as diabetes mellitus, and hyperlipidemia has been argued [16,17]. H. pylori on a human host causes neutrophils and monocyte stimulation and many pro-inflammatory cytokine releases that cause gastric mucosal injury. Although $H$. pylori is a noninvasive organism, because of the antigenic substances it produces, such as heat shock protein, urease, and lipopolysaccharide, it activates $\mathrm{T}$ cells. With an improved antigen presentation, IL-1, IL-6, IL-8, inflammatory cytokines, such as tumor necrosis factor-alpha (TNF-alfa), are released. In addition to that, B-cell response is produced both locally and systemically [18]. Activation of leukocytes occurs as a result of chronic inflammation; in other words, leukocytes have a role in chronic diseases, such as diabetes, hypertension, atherogenesis, thrombosis formation and other inflammatory disorders [19].

In our study, we investigated the $H$. pylori infection activity in patients with dyspepsia symptoms and the relationship between inflammatory markers, neutrophil/lymphocyte ratio and platelets/lymphocyte ratio. In this study we conducted, we could not observe a significant difference in leukocyte, lymphocyte, platelet, NLR and PLR levels between positive/negative H. pylori patients. Guclu et al. have evaluated patients with antral gastritis with endoscopy in the study they carried out in 2017. These patients were classified in four groups as H. pylori negative, mild, moderate and severe and in the study conducted on 199 patients, it was observed that patients that were $H$. pylori positive had a lower NLR compared to patients with negative H. pylori. However, peripheral blood lymphocyte values and platelet counts in patients that were severely H. pylori positive had been detected to be higher compared to negative patients [20]. In another study, patients that were H. pylori positive had been observed to have higher leucocyte, neutrophil and NLR levels compared to $H$. pylori-negative patients, independent from the bacterial Cytotoxin-linked genes, without taking the Cag A conditions and peptic ulcer into consideration [7]. Nalbant et al. conducted a study on 91 patients who had gastrointestinal endoscopy upon dyspeptic complaints. They found out that patients who were H. pylori positive had an apparent reduction in the number of neutrophils, lymphocytes and NLR in their blood, where only the neutrophils decrease was determined to be statistically significant [21]. We think that the lower number of NLR in the H. pylori positive group might be related to the small sample size. Nalbant et al. also determined that within the same study, the platelet values of the $H$. pylori positive group were lower, compared to the $H$. pylori negative group. In a study conducted by Asil et al. in 2016 with 286 patients who had chronic H. pylori infection and 130 H. pylori negative control group, it was found that patients with chronic $H$. pylori infection had a higher NLR level compared to the H. pylori negative group and they observed a decline in NLR with $H$. pylori eradication. In this study, Asil et al. report a remarkable finding that H. pylori eradication leads to a decline in NLR rates [22].

Reviewing the literature, it is suggested that this might be an important marker to foresee the PLR in prognosis of hepatocellular carcinoma, breast cancer and lung cancer [23-25]. In addition, it may be effective in demonstrating the seriousness of coronary artery disease and cardiac damage due to atherosclerotic plaque damage [26]. When all these studies are evaluated together, PLR is expected to be affected by H. pylori infection, which causes a chronic inflammation. Farah et al. have conducted studies on this topic in 2014 and 2017, suggesting that NLR and PLR of H. Pylori-positive patients are higher than H. Pylori-negative patients $[27,28]$. Shimoyama et al. have studied the relationship between NLR-PLR and mortality in the presence of a gastrointestinal perforation, which is a heavy inflammatory case and scales that reflect other inflammatory cases. Their study has retrospectively evaluated 32 patients with gastrointestinal perforation; it has found NLR and PLR to demonstrate mortality with patients who have gastrointestinal perforation much better compared to other prognostic indices that show inflammation [29]. We could not, however, find a correlation between the presence of $H$. pylori infection and NLR and PLR, in our study. Umit et al. have observed that patients with H. Pylori have lower platelet counts compared to patients who are $H$. Pylori negative, in their retrospective search conducted on 4823 patients in 2015. Even though these patients had platelet counts within the normal range, since they had a lower platelet count compared to the H. pylori negatives, it was suggested 
that $H$. pylori reduces the platelet values before immune cytopenia effects the platelets [30]. When we evaluate our work, H. pylori-positive patients and $H$. pylori-negative patients have not demonstrated a statistically significant difference. This finding can be explained by the fact that our study had fewer patients contributing compared to the study of Umit et al.

In our study, H. pylori-positive patients had lower folic acid, iron and ferritin levels than the negative ones (Table 1). Several pathways are blamed for decreased iron stores in the H. pylori-positive patients, including chronic gastritis with achlorhydria, reduced ascorbic acid secretion in the gastric mucosa, iron uptake by the bacterium, and bleeding ulcers related to H. pylori [31]. However, the studies that assess the effect of $H$. pylori eradication therapy on the improvement of iron deficiency are controversial [32]. Some of the studies hypothesize that eradication therapy for H. pylori improves the response of iron replacement therapy, which was previously refractory [33,34]. Therefore, additional studies are needed to clarify whether there is a casual relationship between $H$. Pylori and iron deficiency. Furthermore, we determined that the NLP and PLR are inversely correlated with serum iron and ferritin levels (Table 2). The importance of iron for immunity appears in immune cell proliferation, especially lymphocytes [35]. This may be a possible explanation for the correlation between iron related parameters and NLP and PLR.

There are some limitations of this study. First the retrospective design of the study makes it difficult to establish the cause and effect relationship. Second, we practiced on hematimetric indices to assess the inflammation of $H$. pylori-positive patients. However, it would certainly be better to add the measurement of other known inflammatory markers such as TNF-alfa, IL-1, IL-6 and IL-8. Finally, some of the patients had a limited number of biopsies, which can reduce the accuracy regarding H. pylori infection.

\section{Conclusions}

No correlation between $H$. pylori infection, which is a case of chronic inflammation, and NLR-PLR, which are the strongest markers of inflammatory condition, was observed. On the other hand, H. pylori infection is associated with the presence of iron deficiency. Considering what $H$. pylori infection does in relation to the chronic inflammatory response and the markers of $H$. pylori infection, we believe more extensive and prospective studies are required in this field.

Author Contributions: Study concept and design: B.B., O.M. Analysis and interpretation of the data: H.E., D.S. Drafting of the manuscript: H.E., B.B. Statistical Analysis: B.B., O.M. All authors have read and agreed to the published version of the manuscript.

Funding: This research received no external funding.

Conflicts of Interest: All authors report no conflict of interest regarding this study.

\section{References}

1. Go, M.F. Natural history and epidemiology of Helicobacter pylori infection. Aliment. Pharmacol. Ther. 2002, 16 (Suppl. 1), 3-15. [CrossRef]

2. Lúquez, M.A.; Otero, R.W.; Schmulson, M. Enfoque diagnóstico y terapéutico de dispepsia y dispepsia funcional: Qué hay nuevo en el 2019? [Diagnostic and therapeutic approach to dyspepsia and functional dyspepsia:what's new in 2019?]. Rev. Gastroenterol. Peru. 2019, 39, 141-152.

3. Balta, S.; Demirkol, S.; Unlu, M.; Arslan, Z.; Celik, T. Neutrophil to lymphocyte ratio may be predict of mortality in all conditions. Br. J. Cancer 2013, 109, 3125-3126. [CrossRef] [PubMed]

4. Mosso, E.; Bonetto, S.; Longobardi, G.; Abenavoli, L.; Ribaldone, D.G.; Saracco, G.M.; Pellicano, R. Management of functional dyspepsia in the year 2020. A clinical point of view. Minerva Gastroenterol. Dietol. 2020. [CrossRef]

5. Kang, S.J.; Park, B.; Shin, C.M. Helicobacter pylori Eradication Therapy for Functional Dyspepsia: A Meta-Analysis by Region and H. pylori Prevalence. J. Clin. Med. 2019, 8, 1324. [CrossRef]

6. Liu, C.; Li, X. Stage-Dependent Changes in Albumin, NLR, PLR, and AFR are correlated with Shorter Survival in Patients with Gastric Cancer. Clin. Lab. 2019, 65. [CrossRef] 
7. Jafarzadeh, A.; Akbarpoor, V.; Nabizadeh, M.; Nemati, M.; Rezayati, M.T. Total leukocyte counts and neutrophil-lymphocyte count ratios among Helicobacter pylori-infected patients with peptic ulcers: Independent of bacterial CagA status. Southeast Asian J. Trop. Med. Public Health 2013, 44, 82-88.

8. Bilge, M.; Yeşilova, A.M.; Adas, M.; Helvaci, A. Neutrophil- and Platelet- to Lymphocyte Ratio in Patients with Euthyroid Hashimoto's Thyroiditis. Exp. Clin. Endocrinol. Diabetes 2019, 127, 545-549. [CrossRef]

9. Pacifico, L.; Osborn, J.F.; Tromba, V.; Romaggioli, S.; Bascetta, S.; Chiesa, C. Helicobacter pylori infection and extragastric disorders in children: A critical update. World J. Gastroenterol. 2014, 20, 1379-1401. [CrossRef]

10. Mendoza, E.; Duque, X.; Franco, J.I.H.; Reyes-Maldonado, E.; Morán, S.; Martínez, G.; Rodríguez, A.S.; Martinez, H. Association between Active H. pylori Infection and Iron Deficiency Assessed by Serum Hepcidin Levels in School-Age Children. Nutrients 2019, 11, 2141. [CrossRef]

11. Oporto, M.; Pavez, M.; Troncoso, C.; Cerda, A.; Hofmann, E.; Sierralta, A.; Rios, E.; Coppelli, L.; Barrientos, L. Prevalence of Infection and Antibiotic Susceptibility of Helicobacter pylori: An Evaluation in Public and Private Health Systems of Southern Chile. Pathogens 2019, 8, 226. [CrossRef] [PubMed]

12. Mentis, A.; Lehours, P.; Megraud, F. Epidemiology and Diagnosis of Helicobacter pylori infection. Helicobacter 2015, 20 (Suppl. 1), 1-7. [CrossRef]

13. Breckan, R.K.; Paulssen, E.J.; Asfeldt, A.M.; Kvamme, J.-M.; Straume, B.; Florholmen, J. The All-Age Prevalence ofHelicobacter pyloriInfection and Potential Transmission Routes. A Population-Based Study. Helicobacter 2016, 21, 586-595. [CrossRef]

14. Franceschi, F.; Covino, M.; Baudron, C.R. Review: Helicobacter pylori and extragastric diseases. Helicobacter 2019, 24 (Suppl. 1), e12636. [CrossRef]

15. Mekonnen, H.D.; Fisseha, H.; Getinet, T.; Tekle, F.; Galle, P.R. Helicobacter pylori Infection as a Risk Factor for Hepatocellular Carcinoma: A Case-Control Study in Ethiopia. Int. J. Hepatol. 2018, 2018, 1-7. [CrossRef] [PubMed]

16. He, C.; Yang, Z.; Lu, N.-H. Helicobacter pyloriinfection and diabetes: Is it a myth or fact. World J. Gastroenterol. 2014, 20, 4607-4617. [CrossRef] [PubMed]

17. Jia, E.-Z.; Zhao, F.-J.; Hao, B.; Zhu, T.; Wang, L.-S.; Chen, B.; Cao, K.-J.; Huang, J.; Ma, W.-Z.; Yang, Z.; et al. Helicobacter pylori infection is associated with decreased serum levels of high density lipoprotein, but not with the severity of coronary atherosclerosis. Lipids Health Dis. 2009, 8, 59. [CrossRef] [PubMed]

18. Robinson, K.; White, J.R.; Winter, J.A. Differential inflammatory response to Helicobacter pylori infection: Etiology and clinical outcomes. J. Inflamm. Res. 2015, 8, 137-147. [CrossRef] [PubMed]

19. Rahtes, A.; Geng, S.; Lee, C.; Li, L. Cellular and molecular mechanisms involved in the resolution of innate leukocyte inflammation. J. Leukoc. Biol. 2018, 104, 535-541. [CrossRef] [PubMed]

20. Guclu, M.; Agan, A.F. Association of Severity of Helicobacter pylori Infection with Peripheral Blood Neutrophil to Lymphocyte Ratio and Mean Platelet Volume. Euroasian J. Hepato-Gastroenterol. 2017, 7, 11-16. [CrossRef] [PubMed]

21. Nalbant, A.; Aydin, A. Association of Helicobacter pylori infection with vitamin D, hemogram parameters, and blood group. Turk. J. Acad. Gastroenterol. 2017, 16, 1-5.

22. Asil, M.; Dertli, R. Neutrophil to lymphocyte ratio is increased in chronic helicobacter pylori infection and returns to normal after successful eradication. J. Turgut Ozal Med. Cent. 2016, 23, 409. [CrossRef]

23. Krenn-Pilko, S.; Langsenlehner, U.; Thurner, E.-M.; Stojakovic, T.; Pichler, M.; Gerger, A.; Kapp, K.S.; Langsenlehner, T. The elevated preoperative platelet-to-lymphocyte ratio predicts poor prognosis in breast cancer patients. Br. J. Cancer 2014, 110, 2524-2530. [CrossRef]

24. Zhang, H.; Gao, L.; Zhang, B.; Zhang, L.; Wang, C. Prognostic value of platelet to lymphocyte ratio in non-small cell lung cancer: A systematic review and meta-analysis. Sci. Rep. 2016, 6, 22618. [CrossRef] [PubMed]

25. Zheng, J.; Cai, J.; Li, H.; Zeng, K.; He, L.; Fu, H.; Zhang, J.; Chen, L.; Yao, J.; Zhang, Y.; et al. Neutrophil to Lymphocyte Ratio and Platelet to Lymphocyte Ratio as Prognostic Predictors for Hepatocellular Carcinoma Patients with Various Treatments: A Meta-Analysis and Systematic Review. Cell. Physiol. Biochem. 2017, 44, 967-981. [CrossRef] [PubMed]

26. Wang, X.; Xie, Z.; Liu, X.; Huang, X.; Lin, J.; Huang, D.; Yu, B.; Hou, J. Association of Platelet to lymphocyte ratio with non-culprit atherosclerotic plaque vulnerability in patients with acute coronary syndrome: An optical coherence tomography study. BMC Cardiovasc. Disord. 2017, 17, 175. [CrossRef] [PubMed] 
27. Farah, R.; Khamisy-Farah, R. Association of Neutrophil to Lymphocyte Ratio with Presence and Severity of Gastritis Due to Helicobacter pylori Infection. J. Clin. Lab. Anal. 2014, 28, 219-223. [CrossRef]

28. Farah, R.; Hamza, H.; Khamisy-Farah, R. A link between platelet to lymphocyte ratio and Helicobacter pylori infection. J. Clin. Lab. Anal. 2018, 32, e22222. [CrossRef]

29. Shimoyama, Y.; Umegaki, O.; Agui, T.; Kadono, N.; Minami, T. Neutrophil to lymphocyte ratio and platelet to lymphocyte ratio are superior to other inflammation-based prognostic scores in predicting the mortality of patients with gastrointestinal perforation. JA Clin. Rep. 2017, 3, 49. [CrossRef]

30. Umit, H.; Umit, E.G. Helicobacter pylori and mean platelet volume: A relation way before immune thrombocytopenia? Eur. Rev. Med. Pharmacol. Sci. 2015, 19, 2818-2823.

31. Burns, M.; Amaya, A.; Bodi, C.; Ge, Z.; Bakthavatchalu, V.; Ennis, K.; Wang, T.C.; Georgieff, M.; Fox, J.G. Helicobacter pylori infection and low dietary iron alter behavior, induce iron deficiency anemia, and modulate hippocampal gene expression in female C57BL/6 mice. PLoS ONE 2017, 12, e0173108. [CrossRef]

32. Muhsen, K.; Cohen, D. Helicobacter pylori Infection and Iron Stores: A Systematic Review and Meta-analysis. Helicobacter 2008, 13, 323-340. [CrossRef]

33. Hacihanefioglu, A.; Edebali, F.; Celebi, A.; Karakaya, T.; Senturk, O.; Hulagu, S. Improvement of complete blood count in patients with iron deficiency anemia and Helicobacter pylori infection after the eradication of Helicobacter pylori. Hepatogastroenterology 2004, 51, 313-315. [PubMed]

34. Fiorini, G.; Bland, J.M.; Hughes, E.; Castelli, V.; Vaira, D. A Systematic Review on Drugs Absorption Modifications after Eradication in Helicobacter pylori Positive Patients undergoing Replacement Therapy. J. Gastrointest. Liver Dis. 2015, 24, 95-100. [CrossRef] [PubMed]

35. Beard, J.L. Iron biology in immune function, muscle metabolism and neuronal functioning. J. Nutr. 2001, 131, 568S-580S. [CrossRef] [PubMed]

(C) 2020 by the authors. Licensee MDPI, Basel, Switzerland. This article is an open access article distributed under the terms and conditions of the Creative Commons Attribution (CC BY) license (http://creativecommons.org/licenses/by/4.0/). 